Zhang Cuihong, Wei Xiaohu, Yang Liguo, He Zhenzhen, Wu Jiaze, Liu Hao, Li Xin and Miao Zongcheng*

\title{
Crystal structure of tetrakis( $n$-butyl)-( $\mu_{2}-1,2-b i s(2-$ oxidobenzoyl)hydrazine-1,2-diido- ${ }^{6} N, O, O^{\prime}: N^{\prime}$, $\left.O^{\prime \prime}, O^{\prime \prime \prime}\right)$ ditin(IV), $\mathrm{C}_{30} \mathrm{H}_{44} \mathrm{~N}_{2} \mathrm{O}_{4} \mathrm{Sn}_{2}$
}

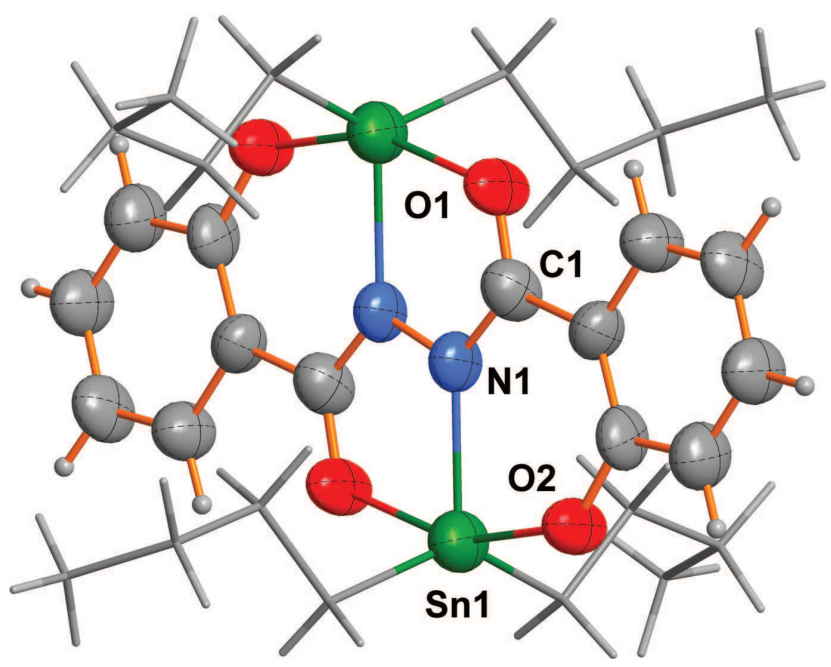

https://doi.org/10.1515/ncrs-2018-0273

Received July 29, 2018; accepted October 24, 2018; available online November 30, 2018

\section{Abstract \\ $\mathrm{C}_{30} \mathrm{H}_{44} \mathrm{~N}_{2} \mathrm{O}_{4} \mathrm{Sn}_{2}, \quad$ monoclinic, $\quad P 2_{1} / c, \quad a=8.8810(8) \AA$, $b=16.8999(13) \AA, \quad c=10.5705(10) \AA, \quad \beta=92.0460(10)^{\circ}$, $V=1585.5(2) \AA^{3}, Z=2, R_{\mathrm{gt}}(F)=0.0660, w R_{\mathrm{ref}}\left(F^{2}\right)=0.1528$, $T=298(2) \mathrm{K}$.}

CCDC no.: 1873753

*Corresponding author: Miao Zongcheng, Key Laboratory of Organic Polymer Photoelectric Materials, School of Science, Xijing University, Xi'an 710123, Shaanxi, P.R. China, e-mail: miaozongcheng@xijing.edu.cn

Zhang Cuihong, He Zhenzhen, Wu Jiaze, Liu Hao and Li Xin: Key Laboratory of Organic Polymer Photoelectric Materials, School of Science, Xijing University, Xi'an 710123, Shaanxi, P.R. China Wei Xiaohu: State Key Laboratory of Special Functional Waterproof Materials, Beijing Oriental Yuhong Waterproof Technology Co., Ltd, Beijing 101309, P.R. China

Yang Liguo: College of Chemistry and Environmental Engineering, Anyang Institute of Technology, Anyang 455000, Henan, P.R. China

Table 1: Data collection and handling.

Crystal:

Size:

Wavelength:

$\mu$ :

Diffractometer, scan mode:

$\theta_{\max }$, completeness:

$N(h k l)_{\text {measured }}, N(h k l)_{\text {unique }}, R_{\text {int }}$ :

Criterion for $I_{\mathrm{obs}}, N(h k)_{\mathrm{gt}}$ :

$N(\text { param })_{\text {refined }}$ :

Programs:

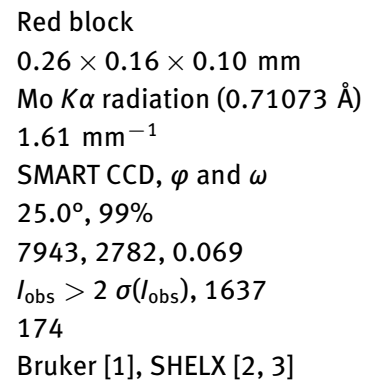

The crystal structure is shown in the figure. Tables 1 and 2 contain details on crystal structure and measurement conditions and a list of the atoms including atomic coordinates and displacement parameters.

\section{Source of material}

$N$-(2-hydroxybenzoyl)-2-hydroxybenzoyl hydrazide was synthesized according to the reference [4]. The other reagents were commercially available and used as purchased $[2,3,5]$.

\section{Experimental details}

A mixture of bissalicylhydrazide ( $88.88 \mathrm{mg}, 0.4 \mathrm{mmol})$, tetrabutylammonium hydroxide (103.79 mg, $0.4 \mathrm{mmol}$ ), dibutyltin dichloride $(208.42 \mathrm{mg}, 0.8)$ and methanol $(10 \mathrm{~mL})$ heated at $60{ }^{\circ} \mathrm{C}$ for $10 \mathrm{~h}$, and then cooled to room temperature. The resulting block crystals of the compound were obtained and washed with distilled water. The yield is ca. $25 \%$. IR(KBr): 3217(s), 1518(s), 1519(s), 1416(s), 1405(s), 1319(s), 1216(s), 1116(s), 1105(s), 1012(s), 1001(s), 915(s), 819(s), 804(m), 761(m), 721(m), 600(m), 444(m) $\mathrm{cm}^{-1}$.

\section{Comment}

Acyl hydrazide complexes have been an important research subject for their extensive biological and pharmacological activity [4]. The activity of its derivatives increased significantly when it formed a stable complex with metal cations in biological cells. In the ligand structure of $o$-carboxyl, hydroxyl benzoylhydrazide, which is located in the ortho carboxyl 
Table 2: Fractional atomic coordinates and isotropic or equivalent isotropic displacement parameters $\left(\AA^{2}\right)$.

\begin{tabular}{|c|c|c|c|c|}
\hline Atom & $x$ & $y$ & $z$ & $U_{\text {iso }} * / U_{\text {eq }}$ \\
\hline Sn1 & $0.72189(7)$ & $-0.01162(4)$ & $0.43518(5)$ & $0.0693(3)$ \\
\hline N1 & $0.9354(7)$ & $0.0048(3)$ & $0.5363(6)$ & $0.0582(17)$ \\
\hline 01 & $1.1006(7)$ & $0.0310(4)$ & $0.6964(5)$ & $0.0813(18)$ \\
\hline 02 & $0.6280(7)$ & $0.0155(4)$ & $0.6044(5)$ & $0.0804(18)$ \\
\hline C1 & $0.9675(11)$ & $0.0221(5)$ & $0.6546(8)$ & $0.064(2)$ \\
\hline $\mathrm{C} 2$ & $0.8425(9)$ & $0.0318(5)$ & $0.7442(7)$ & $0.0604(19)$ \\
\hline C3 & $0.8943(10)$ & $0.0495(5)$ & $0.8696(7)$ & $0.067(2)$ \\
\hline H3 & 0.9972 & 0.0533 & 0.8881 & $0.081^{\star}$ \\
\hline C4 & $0.7939(10)$ & $0.0612(5)$ & $0.9641(8)$ & $0.075(2)$ \\
\hline H4 & 0.8294 & 0.0688 & 1.0470 & $0.090^{\star}$ \\
\hline C5 & $0.6442(11)$ & $0.0617(5)$ & $0.9367(8)$ & $0.074(2)$ \\
\hline H5 & 0.5768 & 0.0727 & 0.9997 & $0.089^{\star}$ \\
\hline C6 & $0.5925(10)$ & $0.0462(5)$ & $0.8166(8)$ & $0.076(2)$ \\
\hline H6 & 0.4891 & 0.0460 & 0.7992 & 0.091 * \\
\hline $\mathrm{C} 7$ & $0.6888(10)$ & $0.0307(5)$ & $0.7195(7)$ & $0.063(2)$ \\
\hline C8 & $0.763(2)$ & $-0.3159(10)$ & $0.4022(18)$ & $0.248(8)$ \\
\hline $\mathrm{H} 8 \mathrm{~A}$ & 0.6814 & -0.3104 & 0.3405 & $0.372^{\star}$ \\
\hline H8B & 0.7785 & -0.3709 & 0.4209 & $0.372^{\star}$ \\
\hline $\mathrm{H} 8 \mathrm{C}$ & 0.8528 & -0.2938 & 0.3693 & $0.372^{\star}$ \\
\hline $\mathrm{C} 9$ & $0.7244(17)$ & $-0.2733(7)$ & $0.5200(16)$ & $0.188(5)$ \\
\hline H9A & 0.7783 & -0.2968 & 0.5921 & $0.226^{\star}$ \\
\hline H9B & 0.6173 & -0.2778 & 0.5333 & $0.226^{*}$ \\
\hline C10 & $0.7681(14)$ & $-0.1853(7)$ & $0.5085(15)$ & $0.165(5)$ \\
\hline $\mathrm{H} 10 \mathrm{~A}$ & 0.7737 & -0.1629 & 0.5930 & $0.198^{\star}$ \\
\hline H10B & 0.8685 & -0.1828 & 0.4755 & $0.198^{\star}$ \\
\hline C11 & $0.6661(12)$ & $-0.1330(6)$ & $0.4267(11)$ & $0.119(4)$ \\
\hline $\mathrm{H} 11 \mathrm{~A}$ & 0.5632 & -0.1395 & 0.4527 & $0.143^{*}$ \\
\hline $\mathrm{H} 11 \mathrm{~B}$ & 0.6703 & -0.1505 & 0.3395 & $0.143^{*}$ \\
\hline C12 & $0.775(2)$ & $0.2489(9)$ & $0.1736(15)$ & $0.230(7)$ \\
\hline $\mathrm{H} 12 \mathrm{~A}$ & 0.8786 & 0.2369 & 0.1606 & $0.346^{\star}$ \\
\hline H12B & 0.7546 & 0.3029 & 0.1505 & $0.346^{\star}$ \\
\hline $\mathrm{H} 12 \mathrm{C}$ & 0.7119 & 0.2145 & 0.1221 & $0.346^{*}$ \\
\hline C13 & $0.7411(17)$ & $0.2367(7)$ & $0.3107(15)$ & $0.174(5)$ \\
\hline H13A & 0.6339 & 0.2439 & 0.3216 & $0.209^{\star}$ \\
\hline H13B & 0.7940 & 0.2766 & 0.3611 & $0.209^{\star}$ \\
\hline C14 & $0.7875(14)$ & $0.1546(6)$ & $0.3589(13)$ & $0.151(4)$ \\
\hline $\mathrm{H} 14 \mathrm{~A}$ & 0.8747 & 0.1368 & 0.3140 & $0.181^{\star}$ \\
\hline H14B & 0.8165 & 0.1581 & 0.4481 & $0.181^{*}$ \\
\hline C15 & $0.6617(11)$ & $0.0941(5)$ & $0.3414(10)$ & $0.100(3)$ \\
\hline H15A & 0.6435 & 0.0837 & 0.2519 & 0.119* \\
\hline H15B & 0.5696 & 0.1149 & 0.3753 & $0.119^{\star}$ \\
\hline
\end{tabular}

group, the hydroxyl group and the amide group have a variety of structure and properties when they coordinate with metal [4-6]. The hydrazide complexes containing tin(IV) are rare.

The compound crystallizes in the monoclinic space group $P 2_{1} / \mathrm{c}$ with two formula units in the unit cell. As shown in Figure 1, one formula unit consists of one acyl hydrazide ligands, two Sn atoms and four butyl groups. Each Sn ion is fivefold coordinated with one nitrogen atoms, two oxygen atoms from the acyl hydrazide ligand and two carbon atoms from butyl groups. The bond length of $\mathrm{Sn}-\mathrm{N}$ is $2.161 \AA$, while the bond length of Sn-O range from $2.052 \AA$ A to $2.164 \AA$, the bond length of $\mathrm{Sn}-\mathrm{C}$ are $2.103 \AA$ and $2.111 \AA$.

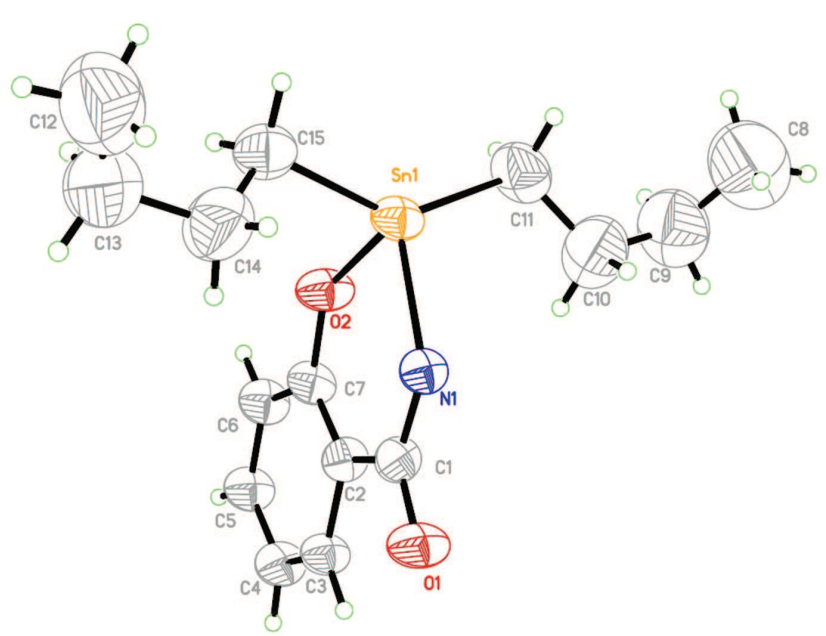

Figure 1: The molecule structure of the compound.

Acknowledgements: This work was supported by the National Natural Science Foundation of China (Grant No. 51602007, Grant No. 51673157), the Natural Science Basic Research Plan in Shaanxi Province of China (Grant No. 2017JM5134, Grant No. 2018JM5047), Scientific Research Program Funded by Shaanxi Provincial Education Department (Grant No. 18JK1206), the Science Research Foundation of Xijing University (Grant No. XJ17B07), the National Students' Platform for Innovation and Entrepreneurship Training Program (Grant No. 201812715003).

\section{References}

1. Bruker. SMART and SAINT for Windows NT Software Reference Manuals, Version 5.0, Bruker Analytical X-Ray Systems, Madison, WI (1997).

2. Sheldrick, G. M.: SADABS, a Software for Empirical Absorption Correction. University of Göttingen, Göttingen, Germany (1997).

3. SHELXL Reference Manual, version 5.1. Bruker Analytical X-Ray Systems, Madison, WI (1997).

4. Moon, D.; Lah, M. S.: Size and shape selectivity of host networks built based on tunable secondary building units. Inorg. Chem. 44 (2005) 1934-1940.

5. Mondal, S.; Schwederski, B.; Frey, W.; Fiedler, J.; Záliš, S.; Kaim, W.: At the borderline between metal-metal mixed valency and a radical bridge situation: four charge states of a diruthenium complex with a redox-active bis(mer-tridentate) ligand. Inorg. Chem. 57 (2018) 3983-3992.

6. Cheaib, K.; Martel, D.; Clément, N.; Eckes, F.; Kouaho, S.; Rogez, G.; Dagorne, S.; Kurmoo, M.; Choua, S.; Welter, R.: Structural, magnetic and optical properties of an Felll dimer bridged by the meridional planar divergent $\mathrm{N}, \mathrm{N}^{\prime}$-bis(salicyl)hydrazide and its photo- and electro-chemistry in solution. Dalton Trans. 42 (2013) 1406-1416. 